\title{
KEPUTUSAN PEMBELIAN ULANG DITINJAU DARI CITRA MEREK, MEDIA IKLAN, DAN BRAND TRUST PADA PRODUK IMBOOST DI SURAKARTA
}

\author{
Mahartiwi Kusuma Wardhani, Sudarwati, Ida Aryati, Sitti Mukarromah \\ Fakultas Ekonomi Manajemen Universitas Islam Batik Surakarta \\ Email :mahartiwi6@gmail.com
}

\begin{abstract}
Abstrak : This study aims to examine the effect of Brand Image, Advertising Media, and Brand Trust on repurchase decisions. The population in this study is an infinite number of consumers in Surakarta. The sampling technique in this study used purposive sampling which resulted in a sample of 100 respondents. The data used in this study are primary data collected by filling out questionnaires. The results of this study indicate that Brand Image has a positive and significant effect on repurchase decisions, Advertising Media has a positive and significant effect on repurchase decisions, and Brand Trust has a positive and significant effect on repurchase decisions.
\end{abstract}

Keywords: Brand Image, Advertising Media, and Brand Trust

\section{PENDAHULUAN}

Produk multivitamin pada saat ini telah berkembang sedemikian rupa, seiring dengan perubahan pola hidup masyarakat yang semakin aware dengan kesehatan serta didukung adanya peningkatan pendapatan masyarakat menyebabkan konsumsi masyarakat akan produk multivitamin mengalami peningkatan. Perusahaan harus memperhatikan apa yang melandasi seorang konsumen dalam memilih suatu produk, hal ini mewujudkan keinginan konsumen dalam membuat keputusan pembelian ulang yang muncul setelah adanya proses evaluasi dalam membuat pilihan mengenai produk yang hendak dibeli berdasarkan kepuasan konsumen pada suatu produk.

Pembelian ulang disebut juga keinginan dan tindakan konsumen untuk membeli ulang suatu produk karena adanya kepuasan yang diterima sesuai dengan yang diiginkan dari suatu produk. Maka dari itu Menurut Schiffman \& kanuk (2008:506) perilaku pembelian ulang itu berhubungan erat dengan konsep dari brand loyalty, yang diusahakan oleh kebanyakan perusahaan karena menyumbang kepada stabilitas yang lebih besar dipasar.

Merek sering di sebut salah satu faktor penting dalam kegiatan pemasaran karena kegiatan memperkenalkan serta menawarkan produk dan jasa tidak terlepas dari merek yang dapat diandalkan. Merek Menurut Ginting (2011:99) mendefinisikan Citra merek adalah suatu nama, istilah, simbol, tanda, desain atau kombinasi dari padanya untuk menandai produk atau jasa dari pesaing. Dalam proses pengembangan citra merek harus diketahui bahwa merek yang kuat memiliki identitas yang jelas.

Setiap perusahaan harus pandai merancang program serta strategi pemasaran yang baik terutama dalam hal komunikasi pemasaran. Salah satu cara untuk memasarkan produk menggunakan media iklan, Media iklan yaitu komunikasi non pribadi melalui bermacam - macam media yang dibayar oleh sebuah perusahaan bisnis atau organisasi nirlaba atau individu yang dalam 
beberapa cara teridentifikasi dalam periklanan dan berharap menginformasikan atau membujuk anggota-anggota dari pemirsa tertentu (Thomas W. Zimmerer, 2010).

Kepercayaan dapat dibentuk secara langsung, formasi kepercayaan secara langsung pada merek keyakinan juga sangat penting. Kepercayaan pelanggan pada merek (Brand Trust) didefinisikan sebagai keinginan pelanggan untuk bersandar pada sebuah merek dengan risiko-risiko yang dihadapi karena ekspektasi pada merek itu akan menyebabkan hasil yang positif (Tjahyadi 2014). Dengan adanya hal tersebut memunculkan adanya kepercayaan konsumen,

Sekarang ini banyak orang yang lebih menjaga kebersihan, memilih makanan yang higienis, dan menjaga daya tahan tubuh untuk meningkatkan imunitas tubuh. Produk - produk multivitamin yang menawarkan berbagai macam manfaat. Salah satu produk multivitamin yang banyak digemari masyarakat yaitu Merek Imboost. Merek imboost banyak mengeluarkan berbagai macam sediaan contohnya seperti Imboost Tablet, Imboost Force, Imboost Effervesen, Imboost Lozenges, dan Imboost kids Syrup. Imboost dipercaya dapat meningkatkan daya tahan tubuh. Produk yang tersebar di Surakarta terdapat berbagai macam produk multivitamin salah satunya produk Imboost yang sangat digemari oleh banyak konsumen karena dilihat dari khasiat produk tersebut. Produk Imboost memiliki khasiat lebih dari produk lainnya, karena produk Imboost terbuat dari bahanbahan alami dari tanaman herbal yaitu Ekstrak Echinachea digunakan sebagai bahan utama serta adapula bahan-bahan aktif lainnya yaitu Ekstrak black elderberry dan Zinc Picolinate sehingga konsumen lebih percaya pada produk Imboost apabila dikonsumsi jangka panjang/ jangka pendek tidak menimbulkan efek samping sedangkan multivitamin yang beredar dipasaran kebanyakan terdapat kandungan obat kimia seingga dapat menimbulkan efek samping jika dikonsumsi jangka panjang.

\section{LANDASAN TEORI}

\section{Keputusan Pembelian Ulang}

Hawkins dkk (2007) pembelian kembali sebagai suatu kegiatan membeli kembali yang dilakukan oleh konsumen terhadap suatu produk dengan merek yang sama tanpa diikuti oleh perasaan yang berarti terhadap produk tersebut.

\section{Citra Merek}

Menurut Tjiptono (2015:49). Citra merek adalah deskripsi asosiasi dan keyakinan konsumen terhadap merek tertentu. Citra merek(brand image) adalah pengamatan dan kepercayaan yang digenggam konsumen seperti yang dicerminkan di asosiasi atau di ingatan konsumen.

\section{Media Iklan}

Menurut Kotler dan Keller (2009:202) "periklanan/advertising adalah semua bentuk terbayar atas presentasi nonpribadi dan promosi ide, barang atau jasa oleh sponsor yang jelas".

\section{Brand Trust}

Kepercayaan dapat digunakan sebagai skala pengukuran rasa suka terhadap merek, dimana rasa suka seorang pembeli terhadap merek termasuk ke dalam tingkatan keempat loyalitas pada piramida loyalitas merek (Aaker, 2008:66). 


\section{Kerangka Pemikiran}

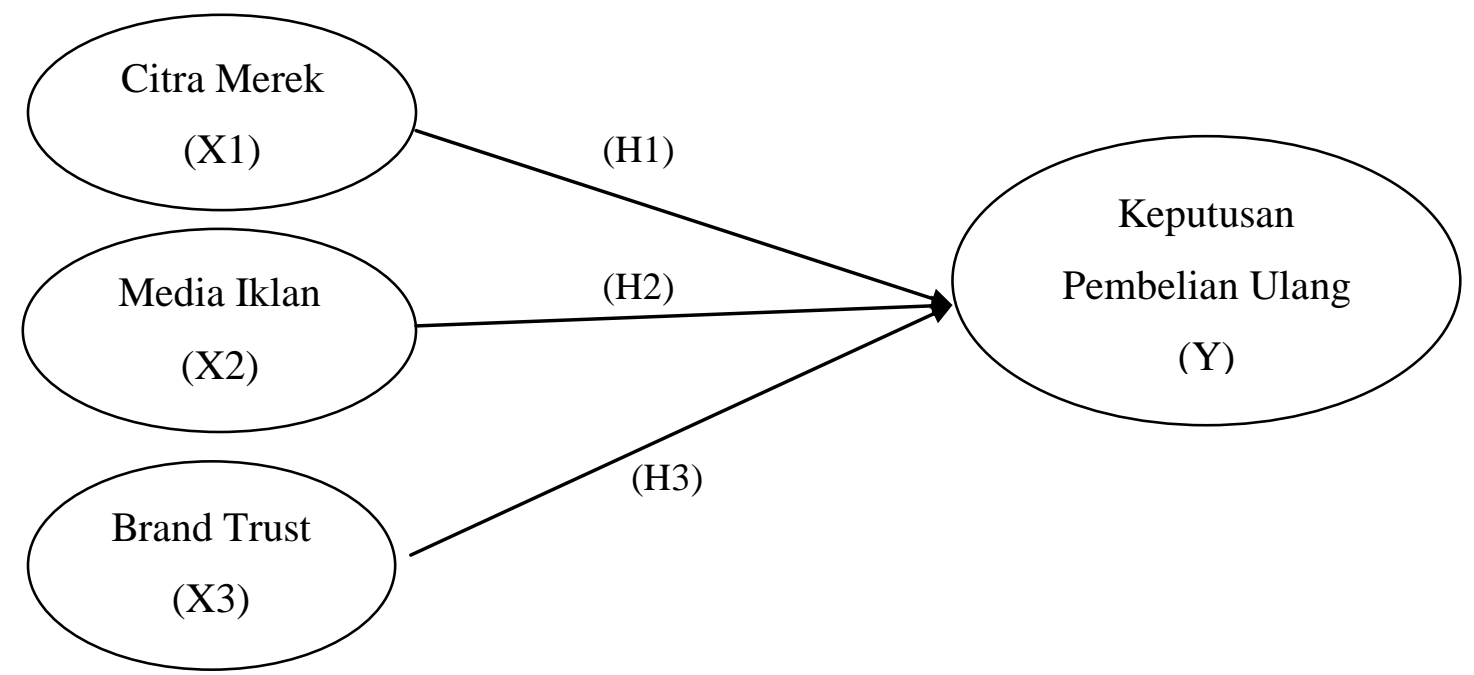

Berdasarkan kerangka pemikiran diatas maka hipotesis pada penelitian ini antara lain : H1 : Terdapat Pengaruh antara Citra Merek terhadap keputusan pembelian ulang H2 : Terdapat Pengaruh antara Media Iklan terhadap keputusan pembelian ulang H3 : Terdapat Pengaruh antara Brand Trust terhadap keputusan pembelian ulang

\section{METODE PENELITIAN}

\section{Desain Penelitian}

Penelitian ini menggunakan metode kuantitatif. Metode penelitian kuantitatif adalah metode penelitian yang digunakan untuk meneliti pada populasi atau sampel tertentu, pengumpulan data menggunakan instrumen penelitian, analisis data bersifat kuantitatif/statistik yang diangkakan, dengan tujuan untuk menguji hipotesis yang telah ditetapkan.

\section{Populasi dan Sampel Penelitian}

Populasi dalam penelitian ini adalah konsumen yang lebih dari dua kali dan pernah membeli produk imboost di Surakarta yang jumlah populasinya tidak terhingga (unkonown populations). Jumlah sampel pada penelitian ini yaitu 100 responden. Sampel diperoleh menggunakan teknik Purposive Sampling.

\section{Sumber Data}

Data primer pada penelitian ini menyebarkan kuisioner kepada para konsumen pelanggan produk Imboost di Surakarta. Sedangkan untuk Data sekunder pada penelitian ini berupa bukubuku dan jurnal ilmiah yang berkaitan dengan penelitian ini.

\section{Teknik Pengumpulan Data}

1) Observasi

Cara pengambilan data dengan mengadakan pengamatan secara langsung terhadap masalah yang sedang diteliti, dengan maksud untuk membandingkan keterangan-keterangan yang diperoleh dengan kenyataannya. 
2) Dokumentasi

Dokumentasi merupakan catatan peristiwa yang sudah berlalu. Dokumen bisa berbentuk tulisan, gambar, atau karya-karya monumental dari seseorang.

3) Kuesioner

Kuesioner adalah teknik pengumpulan data dengan cara peneliti memberikan daftar pertanyaan atau pernyataan yang tertulis untuk dijawab oleh responden.

Pernyataan dalam kuesioner dibuat dengan memberikan skor dalam masing-masing jawaban responden dengan skala Likert berisi 5 tingkatan preferensi jawaban sebagi berikut:

$\mathrm{SS}=$ Untuk jawaban sangat setuju $\quad \mathrm{TS}=$ Untuk jawaban tidak setuju

$\mathrm{S}=$ Untuk jawaban setuju

STS = Untuk jawaban sangat tidak setuju

$\mathrm{KS}=$ Untuk jawaban kurang setuju

\section{Definisi Operasional Variabel}

Dalam penelitian ini menggunakan variabel dependen yaitu keputusan pembelian ulang dan variabel independent yaitu Citra Merek, Media Iklan, dan Brand Trust. Berikut penjelasan mengenai masing-masing variabel tersebut:

\section{Keputusan Pembelian Ulang}

Keputusan pembelian ulang merupakan keinginan dan tindakan konsumen untuk membeli ulang suatu produk karena adanya kepuasan yang diterima sesuai dengan yang diiginkan dari suatu produk.

\section{Citra Merek}

Citra merek adalah representasi dari keseluruhan persepsi terhadap merek dan dibentuk dari informasi dan pengalaman terhadap merek itu.

\section{Media Iklan}

Media iklan adalah Suatu alat yang digunakan untuk memasarkan produk dalam dunia maya yang mempunyai tujuan supaya banyak orang yang mengetahui produk tersebut.

\section{Brand Trust}

Brand trust adalah pengukuran kepercayaan yang diberikan masyarakat kepada produk tertentu berdasarkan informasi dan pengalaman.

\section{HASIL DAN PEMBAHASAN}

\section{Hasil}

\section{Uji Validitas}

1. Keputusan Pembelian Ulang

Tabel 1

Hasil Uji Keputusan Pembelian Ulang

\begin{tabular}{cccc}
\hline Pertanyaan & r hitung & r tabel & Keterangan \\
\hline KPU, 1 & 0,821 & 0,444 & Valid \\
KPU, 2 & 0,617 & 0,444 & Valid
\end{tabular}




\begin{tabular}{llll} 
KPU,3 & 0,526 & 0,444 & Valid \\
KPU,4 & 0,628 & 0,444 & Valid \\
KPU,5 & 0,789 & 0,444 & Valid \\
\hline
\end{tabular}

Sumber: data primer diolah, 2021 terlampir

2. Citra Merek

Tabel 2

Hasil Uji Citra Merek

\begin{tabular}{cccc}
\hline Pertanyaan & r hitung & r tabel & Keterangan \\
\hline C,1 & 0,799 & 0,444 & Valid \\
C,2 & 0,713 & 0,444 & Valid \\
C,3 & 0,798 & 0,444 & Valid \\
C,4 & 0,755 & 0,444 & Valid \\
C,5 & 0,912 & 0,444 & Valid \\
\hline
\end{tabular}

Sumber: data primer diolah, 2021 terlampir

3. Media Iklan

Tabel 3

Hasil Uji Validitas Media Iklan

\begin{tabular}{cccc}
\hline Pertanyaan & r hitung & r tabel & Keterangan \\
\hline MI,1 & 0,775 & 0,444 & Valid \\
MI,2 & 0,704 & 0,444 & Valid \\
MI,3 & 0,705 & 0,444 & Valid \\
MI,4 & 0,688 & 0,444 & Valid \\
MI,5 & 0,831 & 0,444 & Valid \\
\hline
\end{tabular}

Sumber: data primer diolah 2021, terlampir

4. Brand Trust

Tabel 4

Hasil Uji Validitas Media Iklan

\begin{tabular}{cccc}
\hline Pertanyaan & r hitung & r tabel & Keterangan \\
\hline BT,1 & 0,775 & 0,444 & Valid \\
BT,2 & 0,704 & 0,444 & Valid \\
BT,3 & 0,705 & 0,444 & Valid \\
BT,4 & 0,688 & 0,444 & Valid \\
BT,5 & 0,831 & 0,444 & Valid \\
\hline
\end{tabular}

Sumber: data primer diolah 2021, terlampir 


\section{Uji Reliabilitas}

Tabel 5

Hasil Uji Reliabilitas

\begin{tabular}{lcc}
\hline \multicolumn{1}{c}{ Variabel } & Cronbach's Alpha & Keterangan \\
\hline Keputusan Pembelian & 0,766 & Reliabel \\
Citra Merek & 0,806 & Reliabel \\
Kepercayaan Merek & 0,790 & Reliabel \\
Kualitas Produk & 0,789 & Reliabel
\end{tabular}

Sumber : data primer diolah 2021, terlampir

\section{Uji Asumsi Klasik}

Adapun uji asumsi klasik yang dilakukan dalam penelitian ini sebagai berikut :

1. Uji Normalitas

Tabel 6

Hasil Uji Normalitas

\begin{tabular}{|c|c|c|}
\hline Asymp sig 2- tailed & Standar & Kesimpulan \\
\hline 0,537 & 0,05 & Berdistribusi normal \\
\hline
\end{tabular}

Sumber : Data primer diolah 2021

Berdasarkan hasil output nilai Kolmogorov Smirnov adalah 0,805 dan signifikansi 0,537>0,05 maka dapat dikatakan bahwa pernyataan responden tentang keputusan pembelian ulang dalam model penelitian memiliki sebaran data yang normal.

2. Uji Heterokedastisitas

Tabel 7

Hasil Uji Heteroskedastisitas

\begin{tabular}{lcc}
\hline \multicolumn{1}{c}{ Variabel } & $p$-value & Keterangan \\
\hline Citra Merek & 0,307 & Tidak terjadi heteroskedastisitas \\
Media Iklan & 0,463 & Tidak terjadi heteroskedastisitas \\
Brand Trust & 0,744 & Tidak terjadi heteroskedastisitas \\
\hline
\end{tabular}

Sumber : Data primer diolah, 2021

Berdasarkan kesimpulan Hasil Uji Heteroskedastisitas dalam tabel 6 tersebut menunjukan bahwa semua variabel bebas menunjukkan nilai p-value lebih besar dari 0,05 sehingga secara keseluruhan dapat di simpulkan bahwa model regresi tersebut bebas dari adanya gejala heteroskedastisitas.

3. Uji Multikolinearitas

Tabel 8

Hasil Uji Multikolinearitas

\begin{tabular}{lccc}
\hline Variabel & Tolerance & VIF & Keterangan \\
\hline Citra Merek & 0,255 & 3,919 & Tidak multikolinieritas \\
Media Iklan & 0,311 & 3,024 & Tidak multikolinieritas \\
Brand Trust & 0,262 & 3,811 & Tidak multikolinieritas \\
\hline
\end{tabular}

Sumber : Data primer diolah, 2021 


\section{Analisis Regresi Berganda}

\section{Tabel 9}

\section{Hasil Uji Regresi Linear Berganda Coefficients $^{\mathrm{a}}$}

\begin{tabular}{|l|c|c|}
\hline \multirow{2}{*}{\multicolumn{1}{|c|}{ Model }} & \multicolumn{2}{|c|}{ Unstandardized Coefficients } \\
\cline { 2 - 3 } & B & Std. Error \\
\hline 11. (Constant) & 3.284 & 1.318 \\
TC & .240 & .107 \\
TMI & .258 & .105 \\
TBT & .293 & .111 \\
\hline
\end{tabular}

a. Dependent Variable: keputusan pembelian ulang

Sumber : Data primer diolah 2021

Berdasarkan hasil pengujian regresi linier berganda diatas, maka diperoleh persamaan regresi sebagai berikut :

Dimana:

$$
\mathrm{Y}=3,284+0,240 \mathrm{X}_{1}+0,258 \mathrm{X}_{2}+0,293 \mathrm{X}_{3}
$$

1) Konstanta $(\alpha)$ sebesar 3,284 yang berarti apabila citra merek, media iklan dan brand trust tetap atau tidak berubah, maka keputusan pembelian ulang produk imboost di Surakarta tetap ada.

2) Koefisien regresi pada variabel citra merek $\left(X_{1}\right)$ sebesar 0,240 menunjukkan bahwa jika citra merek berpengaruh positif terhadap keputusan pembelian ulang,

3) Koefisien regresi pada variabel media iklan $\left(X_{2}\right)$ sebesar 0,258 menunjukkan bahwa jika media iklan berpengaruh positif terhadap keputusan pembelian ulang,

4) Koefisien regresi pada variabel brand trust $\left(\mathrm{X}_{3}\right)$ sebesar 0,293 menunjukkan bahwa jika brand trust berpengaruh positif terhadap keputusan pembelian ulang.

\section{Uji Hipotesis}

Adapun uji hipotesis yang dilakukan dalam penelitian adalah sebagai berikut :

1. Uji F

\section{Tabel 10}

\section{Hasil Uji F}

\begin{tabular}{|l|l|l|l|l|}
\hline F hitung & F tabel & Sig. & Standar & Keterangan \\
\hline 55.734 & 2,47 & $.000^{\mathrm{a}}$ & 0.05 & Model layak \\
\hline
\end{tabular}

Sumber : Data primer diolah 2021

Berdasarkan Tabel 9 menunjukkan nilai $\mathrm{F}$ sebesar 55,734 >dari $\mathrm{F}_{\text {tabel }} 2,47$ dengan probabilitas signifikan 0.000 . Karena probabilitas $<0.05$ dan nilai $\mathrm{F}$ hitung $>\mathrm{F}$ tabel, maka dapat dikatakan bahwa variabel independenmeliputi citra merek,media iklan dan brand trust secara bersama-sama berpengaruh signifikan terhadap variabel keputusan pembelian ulang produk imboost di Surakarta. 
2. Uji Signifikan Parsial (Uji t)

Tabel 11

Hasil Uji t

\begin{tabular}{cccl}
\hline Variabel & t hitung & Sig. & Keterangan \\
\hline Citra merek $\left(\mathrm{X}_{1}\right)$ & 2,252 & 0,027 & H1 terbukti \\
Media iklan $\left(\mathrm{X}_{2}\right)$ & 2,450 & 0,016 & H2 terbukti \\
Brand trust $\left(\mathrm{X}_{3}\right)$ & 2,642 & 0,010 & H3 terbukti \\
\hline
\end{tabular}

Sumber : Data primer diolah, 2021

Hasil tabel 10 hasil uji t dapat dijelaskan sebagai berikut :

1) $\mathrm{H}_{1}=$ variabel citra merek berpengaruh positif dan signifikan terhadap keputusan pembelian ulang produk imboost di Surakarta.

2) $\mathrm{H}_{2}=$ variabel media iklan berpengaruh positif dan signifikan terhadap keputusan pembelian ulang produk imboost di Surakarta.

3) $\mathrm{H}_{3}=$ variabel brand trust berpengaruh positif dan signifikan terhadap keputusan pembelian ulang produk imboost di Surakarta.

3. Uji Koefisien Determinasi $\left(\mathrm{R}^{2}\right)$

\section{Hasil Uji Koefisien Determinasi $\left(\mathbf{R}^{2}\right)$ Model Summary ${ }^{b}$}

\begin{tabular}{|l|r|r|r|c|}
\hline Model & \multicolumn{1}{|c|}{$\mathrm{R}$} & R Square & Adjusted R Square & $\begin{array}{c}\text { Std. Error of the } \\
\text { Estimate }\end{array}$ \\
\hline 1 & $.797^{\mathrm{a}}$ & .635 & .624 & 1.58286 \\
\hline
\end{tabular}

a. Predictors: (Constant), brand trust, media iklan, citra merek

b. Dependent Variable: keputusan pembelian ulang

Sumber : Data primer diolah 2021

Berdasarkan tabel 11 diketahui bahwa Adjusted $R$ Square adalah 0,624 hal ini berarti kemampuan variabel citra merek, media iklan dan brand trust dalam menjelaskan keputusan pembelian ulang produk imboost di Surakarta adalah sebesar 62,4\% sementara sisanya $37,6 \%$ dijelaskan oleh variabel lainya yang tidak diteliti dalam penelitian ini seperti kualitas layanan, kepuasan konsumen, dan kualitas produk.

\section{PEMBAHASAN}

1) Pengaruh citra merek terhadap keputusan pembelian ulang produk imboost di Surakarta

Penelitian yang penulis lakukan menunjukkan bahwa citra merek memiliki pengaruh positif dan signifikan terhadap keputusan pembelian ulang produk imboost diSurakarta. Hal ini mengindikasikan semakin baik citra merek yang dimiliki produk imboost maka akan memberikan pengaruh dalam meningkatkan keputusan pembelian ulang produk tersebut.

Hasil penelitian ini didukung dengan penelitian yang dilakukan oleh Siti dan Rosalina (2019), citra merek secara parsial berpengaruh signifikan terhadap keputusan pembelian ulang. 
2) Pengaruh media iklan terhadap keputusan pembelian ulang produk imboost di Surakarta

Uji hipotesis membuktikan bahwa media iklan dalam memberikan berpengaruh positifterhadap keputusan pembelian ulang produk imboost di Surakarta. Hal ini mengindikasikan semakin efektif periklanan yang dilakukan oleh produk imboost dalam melakukan kegiatan promosi, maka akan berpengaruh dan meningkatkan keputusan pembelian ulang produk imboost di Surakarta.

Hasil penelitian ini didukung dengan hasil penelitian yang telah dilakukan oleh Magfira Nur dan June (2020) yang menyatakan bahwa media iklan berpengaruh signifikan terhadap loyalitas konsumen produk teh botol sosro di kota Bima.

3) PengaruhBrand Trust terhadap keputusan pembelian ulang produk imboost di Surakarta

Uji hipotesis menunjukkan bahwa brand trust berpengaruh positif dan terhadap keputusan pembelian ulang produk imboost di Surakarta. Namun demikian tidak semua konsumen yang mengkonsumsi imboost di Surakarta memiliki kesesuaian dengan kepribadian konsumen. Akan tetapi produk imboost di Surakarta berpendapat bahwa produk imboost dipercaya mampu meningkatkan daya tahan tubuh. Hal ini menunjukkan bahwa brand trust berpengaruh terhadap keputusan pembelian ulang produk imboost di Surakarta.

Hasil penelitian ini didukung oleh Siti dan Rosalina (2019) yang menyatakan bahwa brand trust mempengaruhi keputusan pembelian ulang.Penelitian dengan hasil yang sama oleh Wulansari (2013) yang menyatakan brand trust memiliki pengaruh signifikan terhadappembelian ulang produk Sari Roti di Kota Baru.

\section{KESIMPULAN}

Berdasarkan hasil penelitian dan analisa yang telah dilakukan maka dapat ditarik kesimpulan sebagai berikut :

1) Variabel citra merek, media iklandan brand trustsecara simultan memberikan pengaruh yang cukup besar dalam mempengaruhi keputusan pembelian ulang produk imboost di Surakarta.

2) Variabel citra merek berpengaruh secara positif dan signifikan terhadap keputusan pembelian ulang produk imboost di Surakarta

3) Variabel media iklan berpengaruh secara positifdan signifikan terhadap keputusan pembelian ulang produk imboost di Surakarta.

4) Variabel brand trust berpengaruh secara positif dan signifikan terhadap keputusan pembelian ulang produk imboost di Surakarta.

\section{Saran}

1) Variabel brand trust menempati urutan pertama dalam mempengaruhi keputusan pembelian ulang produk imboost di Surakarta. Meski demikian produk imboost perlu mengupayakan lebih lanjut untuk memberikan informasi mengenai imboost melalui berbagai macam media seperti media sosial.

2) Variabel media iklan memberikan pengaruh kedua dalam menentukan keputusan pembelian ulang produk imboost di Surakarta. Untuk itu produk imboost perlu mempertahankan sebagai produk yang mudah diingat dengan warna kemasan yang keungu-unguan yang selama ini digunakan.

3) Variabel citra merek memberikan pengaruh paling kecil dalam mempengaruhi keputusan pembelian ulang produk imboost, untuk itu perlu diupayakan mempertahankan brand image yang kuat sebagai suplemen meningkatkan daya tahan tubuh dan juga meningkatkan variasi produk dengan aneka rasa sebagai upaya untuk menarik konsumen. 


\section{DAFTAR PUSTAKA}

Arikunto, S. (2010). Prosedure Penelitian Suatu Pendekatan Praktek. Jakarta: Rineka Cipta.

Fakaubun, U. F. (2019). Pengaruh Citra Merek Terhadap Minat Beli Ulang Sepatu Adidas Di Malang Melalui Kepuasan Pelanggan Sebagai Variabel Intervening (Studi Kasus Pada Toko Sport Station Dinoyo, Malang). Jurnal Ilmu Manajemen Volume 4 Nomor 2 September 2019 , 4, 221-234.

Ghozali, I. (2013). Analisis Multivariate dengan program IBSM SPSS21. Semarang: Universitas Diponegoro

Hafizh Novansa, H. A. (2017). Purchase Decision Model: Analysis of Brand Image, Brand Awareness and Price (Case Study SMECO Indonesia SME products). Saudi J. Humanities Soc. Sci.; Vol-2, Iss-8(Aug, 2017) , 2, 621-632.

Haryani, D. S. (2019). Pengaruh Periklanan Dan Promosi Penjualan Terhadap Keputusan Pembelian Pada Perumahan Griya Puspandari Asri Tanjungpinang. Dimensi, Vol. 8, No. 1, 8, 54-70.

Hasugian, J. T. (2015). Pengaruh Brand Image Dan Brand Trust Terhadap Brand Loyalty Telkomsel (Survey Terhadap Pelanggan Telkomsel di Grapari Samarinda). eJournal Ilmu Administrasi Bisnis, Volume 3, Nomor 4, 2015 , 3, 923-937.

Hendra Riki Wijaya, S. R. (2018). The Effect of Trust and Brand Image to Repurchase Intentionin Online Shopping. International Conference on Economics, Business and Economic Education 2018, 915-928.

Heriyanto, A. B. (2017). Pengaruh Brand Equity Dan Brand Trust Terhadap Loyalitas Konsumen Mobil Merek Toyota Kijang Innova (Survey Konsumen Pada Dealer PT. Agung Automall Cabang Sutomo Pekanbaru). JOM FISIP Vol. 4 No. 2 Oktober 2017 , 4, 1-11.

Nafanu, S. (2020). Pengaruh Media Iklan, Pesan Iklan dan Kreativitas Iklan Terhadap Efektivitas Iklan Dalam Menumbuhkan Brand Awareness Produk Lee Minerale Pada Masyarakat Kota Kefamenanu Kabupaten TTU. Jurnal Ekonomi Pembangunan Vol 5 No 3 Sept 2020 , 5, 31-45.

Neni Rambe, C. M. (2017). Pengaruh Pelayanan, Citra Merek Dan Harga Terhadap Pembelian Ulang Melalui Kepuasan Pelanggan Dan Word Of Mouth. Ekobisman Vol 1 No 3 , 1, 241-261.

Ni Made Rahayu Wulandari, I. K. (2015). Pengaruh Celebrity Endorser, Brand Image, Brand Trust Terhadap Keputusan Pembelian Clear Shampoo Di Kota Denpasar. E-Jurnal Manajemen Unud, Vol. 4, No. 11, 2015 , 4, 3909-3935.

Nur Magfira, I. (2020). Pengaruh Media Iklan dan Citra Merek Terhadap Loyalitas Konsumen Pada Produk Teh Botol Sosro (Studi Kasus: Konsumen Kota Bima). Journal of Business and Economics Research (JBE) Vol 1, No 2, June 2020 , 1, 145-149. 
Oddy Adam Noegroho, S. S. (2013). Pengaruh Experiential Marketing Dan Brand Trust Terhadap Kepuasan Pelanggan Dan Loyalitas Pelanggan (Survei Pada Pelanggan Kfc Cabang Kawi Malang). Jurnal Administrasi Bisnis (Jab)|Vol. 6 No. 2 Desember 2013 , 6, 1-7.

Raditya Bayu, Y. L. (2019). Analysis Of The Effect Of Brand Image, Product Quality And Aftersales Service On Repurchase Decision Of Samsung Smartphones. Rjoas, 8(92), August $2019,8,19-32$.

Respati, I. A. (2020). Peran Kepuasan Konsumen Memediasi Hubungan Kualitas Produk Dan Persepsi Harga Dengan Keputusan Pembelian Ulang. E-Jurnal Manajemen, Vol. 9, No. 4, , 9, 1379-1400.

Seong-Soo CHA, B.-K. S. (2019). The Effect of Brand Trust of Home Meal Replacement on Repurchasing in Online Shopping. Journal of Business, Economics and Environmental Studies 9-3 (2019) , 9, 21-26.

Siti Suryani, S. S. (2019). Pengaruh Brand Image, Brand Trust, Dan Kualitas Layanan Terhadap Keputusan Pembelian Ulang Dengan Kepuasan Konsumen Sebagai Variabel Moderating (Studi Pada Startup Business Unicorn Indonesia). Journal of Business Studies Volume 04, No 1, 2019 , 04, 40-53.

Sugiyono. (2014). Metode Penelitian Bisnis (Pendekatan Kuantitatif, Kualitatif Dan $R \& D)$. Bandung: Alfabeta.

Widiyanti, W. (2017). Pengaruh Persepsi Kualitas Produk, Citra Merek dan Media Iklan Instagram terhadap Keputusan Pembelian Produk Ninebox. Cakrawala, Vol. XVII, No. 1, Maret 2017 , XVII, 40-50.

Wulansari, A. (2013). Pengaruh Brand Trust Dan Perceived Quality Terhadap Keputusan Pembelian Ulang Produk Sari Roti (Studi Pada Konsumen di Perumahan Gresik Kota Baru, Manyar Gresik) 